\title{
初中化学生活化教学 “三部曲”
}

\author{
秦颖 \\ 廊坊市第九中学 \\ DOI:10.32629/er.v2i8.1973
}

[摘要] 初中化学教学如何发挥教师主导作用,启迪学生自致其知,把握课前导入、课堂探究、课外延伸生活化教学 “三部曲” 至关重要。课前引入源于生活事例, 使学生在熟悉的生活场景中认识问题; 课堂上引导学生通过生活经验探究知识点, 立足于 问题学习化学知识; 最后指导学生将所学知识运用于生活实际, 提高分析问题解决问题的能力, 最终达到提高学生学科素养的 目的。

[关键词] 初中化学; 生活化教学; 三部曲

陶行知说: “生活教育是给生活以教育, 用生活来教育, 为生活的向前向上的需要而教育……教育要通过生活才能 发出力量而成为真正的教育”。由此可见, 生活是教育的源泉, 教育来源于生活服务于生活。化学教学亦是如此, 生活是化 学教学的肥沃土壤。在化学教学中将课堂学习与生活实践相 结合, 使学生在课堂学习过程中与生活牵手同行, 让化学教 学在科学世界与生活世界的通融中前行, 已成为集众家所长 的有效教学方法。

\section{1 课前导入生活化是激发学习兴趣的前提}

叶圣陶说: “教师之为教, 不在全盘授予, 而在相机诱 导”。课前导入有酛酿情绪, 渗透主题以及带入情境的作用。 因此, 课前导入能否激发学生兴趣、吸引学生注意力决定了 一节课的成败, 更决定了相机诱导的效果。化学知识蕴藏于 生活的方方面面, 需要教师用敏锐的眼光去发现捕捉。从学 生熟知的生活经验出发, 创设学生感兴趣、符合教学内容的 情境导入课程, 可以增添新鲜感, 激发学生学习兴趣和求知 欲望, 使他们感受到课堂的活力、吸引力, 进而对化学课堂产 生亲切感、眷恋感, 学生才能在学习过程中更加积极主动地 参与到教学活动之中; 教师才能捕捉时机、创造条件, 循循 善诱, 帮助学生在发现生活、感受生活的过程中理解、掌握、 运用知识点, 使其真正受到启迪。

例如《燃烧和灭火》的教学片段:

老师: 电视台正在播放一部很火的电视节目一一《爸爸 去哪儿》, 同学们一定都看过吧?

学生: 看过!

老师: 下面我们一起观看一段《爸爸去哪儿》中的视频 片段, 看看这些明星爸爸做了什么, 并思考视频中的干草为 什么没用火柴点燃就能燃烧起来?（播放《爸爸去哪儿》中 钻木取火视频)。

学生: 观看视频并思考, 说出自己的想法。

老师: 及时鼓励学生, 引入新课。

学生在带着问题观看兴趣十足的《爸爸去哪了》中关于 燃烧的视频片段后, 马上就趣味盎然, 沉浸在快乐的学习气 氛中, 好奇心自然而然地产生, 对本节课学习的积极性、主动
性顺理成章形成。同时, 为后续知识点的学习打下了伏笔, 让学生对燃烧条件和灭火原理有了更加深刻的认识。学生对 化学变化观也有了初步认识, 知道化学变化需要一定的条件, 遵循一定规律, 认识化学变化的本质是有新物质生成, 并伴 有能量的转化, 同时提高了证据推理能力, 知道可以通过分 析、推理等方法认识研究对象的本质特征、构成要素及其相 互关系, 学科素养在潜移默化中慢慢地形成。

\section{2 课堂探究生活化是理解掌握新知的关键}

化学课堂教学设计要围绕教学内容着重从化学知识与 生活实际的联系出发, 深入挖掘教材中与生活密切相关的情 景元素, 使学生对问题产生浓厚的兴趣。而课堂教学活动作 为在课堂这一特定环境中进行的特殊活动, 是认知活动、情 感活动、意志活动的有机统一。对此, 在课堂教学中, 以生活 化的教学内容引导学生通过生活经验主动探究知识点, 在探 究中了解知识原理, 寻找解决问题的答案等, 使学生从中悟 出化学知识的生活意义和使用价值, 从而激发学生探究的热 情和动力。同样在讲《燃烧与灭火》这节课时, 设计了一个 “我是小小消防员” 想方设法来熄灭蜡烛火焰的环节。首先 让学生从生活经验入手想办法, 同学们各抒已见, 踊跃发言, 说出了吹灭、用水浇灭、湿布盖灭、剪断烛芯等多种方法。 教师再相机诱导, 让学生讨论每种灭火方法对应的是破坏了 哪个燃烧条件? 在此基础上, 循序渐进, 要求同学们从破坏 燃烧条件的角度思考还有什么方法可以灭火? 有的学生想 出二氧化碳可以灭火, 教师再引导同学们找出生成二氧化碳 的反应, 学生自然而然的设计出在盛有燃烧蜡烛的烧杯中加 入碳酸钠, 再滴入盐酸的实验方案来熄灭蜡烛, 由一名同学 上台完成演示实验。老师趁热打铁, 给学生介绍不熟悉的灭 火器原理, 观看扑灭棉布、油气、实验室精密器材、图书等 火灾的视频, 将所学知识应用到实际生活中。整个探究过程 巧妙地融合生活元素, 以 “激趣” 导入, 以 “设疑一探究” 为 过程, 层层激趣, 步步设疑, 共同探究, 充分体现了以学生为 主体的新课程理念, 学生的创新能力、探究能力、解决实际 问题的能力逐步提高。

在讲复习课时可以创设如下的情景: 小明妈妈是个化学 
老师, 周末妈妈给小明提出一些生活化学化的问题。(1) 早晨 起床后发现是雾䨪天气, 妈妈问小明空气的成分有什么? 这 样的天气主要污染物是什么? 怎样防治空气污染? (2) 中午 做饭时, 妈妈蒸馒头时碱放多了, 问小明用什么办法挽救? 什么原理? 吃饭时饭桌上摆了馒头、红烧肉、鸡蛋汤, 让小 明评价今天的食谱是否科学? 还需要加个什么菜? (3) 吃完 晚饭后, 小明拿出最爱的汽车模型擦拭, 妈妈问汽车模型的 车体、座椅、轮胎、装饰贴纸分别是什么材质的? 分别属于 什么材料? 有什么化学性质? (4) 晚上, 电视报道有居民楼 发生火灾, 用泡沫灭火器进行灭火, 妈妈又问燃烧的条件是 什么? 泡沫灭火器的原理是什么? 若你是小明的智囊团成 员, 你能帮他解决吗? 通过模拟一个个真真切切的生活画面, 并设计一系列与生活息息相关的小实验, 巧妙的将学生融入 到生活化的课堂, 学生的学习兴趣立刻被调动起来, 让枯燥 的复习课堂也能焕发出生命的活力。在激发学生探究热情的 同时, 也能够帮助学生更好地将化学知识与实践应用有机结 合, 从而不断提高学生的化学学科素养。

\section{3 课外延伸生活化是提升实践能力的途径}

生活本身是一个巨大的学习课堂, 教师还应该注重创设 大课堂情境, 鼓励学生在日常生活实践中寻找问题, 诱导学 生对身边的所见所闻发生联想。广泛的、深度的学科实践活 动可以帮助学生深化对学科内容的理解。学科实践活动是指 学生参与的以实践为主要形式的学科学习活动。它具有两个 特点: 一是学生有直接体验, 二是学生有操作行为。实践活 动的对象直接指向生活世界, 主要有学科实验与社会调查两 种。实践活动既能把课堂中所学学科知识与学生实际生活联 系起来, 以加深他们对学科知识的理解、激发其学习兴趣; 更能培养他们在实践过程中发现问题解决问题的能力。一旦 所学的东西被派上用场时, 学生求知的劲头会更大, 跃跃欲 试的愿望会更强烈, 对于延伸课堂、激活知识、提升能力具 有不可估量的作用。此时教师的行为应是充分相信学生的探 究潜能, 鼓励他们进行实验、猜测、推理、创造等活动, 也就 是指导学生 “搞研究”。
为有效推进学科实践活动, 我校组建了 “化学部落” 活 动小组。主要利用业余时间组织课外活动。它既是对课堂教 学的补充, 也是课堂教学的延伸。比如, 在学习空气后, 布置 学生以小组为单位网上查阅资料了解雾䨪是一种什么样的 空气污染物, 对环境有哪些影响, 结合实际总结治理雾䨪有 哪些方法, 并设计出调查问卷, 到小区展开调查并普及环保 知识; 引导学生通过阅读课外书籍、上网查阅资料学习相关 知识, 选择生活中合适的仪器, 设计一些趣味实验, 并通过小 组合作的形式完成实验探究过程, 从而提高学生的观察思考 及动手能力。例如在讲完碱的化学性质后, 学生利用矿泉水 瓶、熟鸡蛋、输液管、小药瓶等生活用品设计了几套验证二 氧化碳与氢氧化钠反应的装置; 开展有关氧气、二氧化碳、 塑料的利与弊辩论赛, 学生的参与度很高, 取得良好效果。从 实际生活应用引导学生进行的科学实践探究活动, 让学生在 提高实践操作能力的同时, 培养了学生搜集处理信息、获取 新知识、分析和解决问题的能力以及交流合作能力, 不仅使 学生知其然, 还能知其所以然, 达到了事半功倍的效果。

初中化学课堂生活化教学 “三部曲”, 利用生活化元素 从课前导入、课堂探究、课外延伸三个层面有效打通课堂教 学与现实生活世界的界限, 让多姿多彩的生活实际成为化学 知识的源头活水, 使学生始终保持对生活和自然界中化学现 象的好奇心和求知欲, 彰显了化学课堂的生命力。

\section{[参考文献]}

[1]林小驹,李跃,沈晓红等.高中化学学科核心素养体系 的构成和特点 [J].教育导刊(上半月),2015(10):78-81.

[2]王建平.学科实践活动课程的探索 [J].中国教师(上半 月),2017(4):14-17.

[3]钟启泉.课堂转型[M]. 华东师范大学出版社,2018:3-6.

[4]余文森.核心素养导向的课堂教学 [M].上海教育出版 社,2017:4-7.

\section{作者简介:}

秦颖(1972--)女, 河北廊坊人, 汉族, 本科, 中学高级教师, 研究方向: 初中化学学科教学; 从事工作: 初中化学教学。 